\title{
LabVIEW-based Remote Laboratory Experiments for a Multi-mode Single-leg Converter
}

\author{
Sertac Bayhan ${ }^{\dagger}$ \\ ${ }^{\dagger}$ Dept. of Electronics and Automation, Ataturk Vocational High School, Gazi University, Ankara, Turkey
}

\begin{abstract}
This study presents the design and implementation of a web-based remote laboratory for a multi-mode single-leg power converter, which is a topic in advanced power electronics course. The proposed laboratory includes an experimental test rig with a multi-mode single-leg power converter and its driver circuits, a measurement board, a control platform, and a LabVIEW-based user interface program that is operated in the server computer. Given that the proposed web-based remote laboratory is based on client/server architecture, the experimental test rig can be controlled by a client computer with Internet connection and a standard web browser. Although the multi-mode single-leg power converter can work at four different modes (main boost, buck-boost, boost-boost, and battery boost modes), only the buck-boost mode is used in the experiment because of page limit. Users can choose the control structure, control parameters, and reference values, as well as obtain graphical results from the user interface software. Consequently, the feedbacks received from students who conducted remote laboratory studies indicate that the proposed laboratory is a useful tool for both remote and traditional education.
\end{abstract}

Key words: LabVIEW, Multi-mode single-leg converter, Power electronics, Real-time control, Web-based laboratory

\section{INTRODUCTION}

At present, educational institutions worldwide aim to improve their educational facilities while decreasing educational costs. When planning an educational facility, designers must consider that learning is not only a process that takes place in the classroom for a short time but as a part of life that continues throughout the lifetime of a person. Therefore, many educational institutions have continuing education units or distance learning schools to extend their educational facilities to a wider population than those in classrooms. Theoretical knowledge can be easily acquired by using distance-learning methods, such as TV programs, videos, or web-based applications. In engineering education, however, theoretical background should be coupled with practical applications. Many institutions and faculties that provide engineering education have laboratories to improve the practical skills of their students. Students work with real devices in these laboratories and prepare themselves for practical applications. Nevertheless, these laboratories assist a

Manuscript received Jul. 9, 2013; accepted Jul. 5, 2014

Recommended for publication by Associate Editor Tae-Woong Kim.

${ }^{\dagger}$ Corresponding Author: sbayhan@gazi.edu.tr

Tel: +90-312-838 68 00, Gazi University

Dept. of Electronics and Automation, Ataturk Vocational High School, Gazi University, Turkey limited number of students at a limited time while increasing costs. Accidents and injury may also occur during experiments as a result of moving parts of experimental sets or from electric shock. Many educational laboratories also have ordinary devices because technological devices are developing rapidly and updating laboratory devices is difficult because of additional costs. Given the limitations of real laboratories, some educational units intend to use web-based laboratories for their educational facilities. Web-based systems that are remotely controlled and monitored are used for educational purposes, as well as in industrial and home automation systems. Therefore, remote laboratories have received increasing interest from researchers in recent years. Related literature indicates that web-based remote laboratories are used in a wide variety of engineering areas. A remote laboratory was used to illustrate several control experiments for control engineering in [1], [2]. A remote laboratory for engineering measurements was used as a power engineering and motion control laboratory for a mechatronic course in [3]-[5]. Web-based laboratories were also used as a configurable electronic laboratory [6], an analog and digital communication laboratory [7], a robotic control laboratory [8], [9], a digital signal processing laboratory [10], and an electrical machine laboratory 
[11]-[15].

Power electronics is a multi-disciplinary engineering area that includes electrical, electronics, computer, control, automotive, and power engineering. Power electronics-based systems are used in a wide range of application areas, such as home appliances, electric vehicles, electric drives, uninterruptible power supplies, and renewable energy sources. Working on power electronics requires some knowledge on circuit theory, control theory, and semiconductors apart from knowledge on the application area. Given the complex structure of power electronics, engineers and engineering students experience difficulties in understanding this area. The development of microprocessor and semiconductor technologies has also enhanced power electronics. Hence, engineers have to keep their knowledge up-to-date. Learning all types of power electronic circuits in a conventional laboratory is difficult because of the large number of circuits that increases daily. To improve effective learning of power electronics, several methods have been suggested. In [16], the hardware and software modules of an Internet-based remote laboratory for multi-level power converters were described. Users can control a multi-level converter through the Internet by selecting the control structure, control parameters, and load types, as well as obtain the graphical results of the measurements. A software-reconfigurable e-learning platform for power electronics courses was proposed in [17], and a configurable power electronic test bed was developed to realize circuit topologies and control techniques of power electronic circuits. An Internet-based simulation tool for DC/DC converters was proposed in [18]. DC/DC converters, buck, boost, and buck-boost were modeled separately and simulated through the Internet.

A multi-mode single-leg power converter suggested in [19] has become a topic in advanced power electronics and is used for energy conversion in electric cars, wind turbines, and solar energy systems. Multi-mode single-leg power converters can work at four modes and boost the main source voltage while charging/discharging storage devices such as batteries and/or ultra-capacitors.

In this study, a new web-based remote laboratory for a multi-mode single-leg converter is designed and implemented as part of an advanced power electronics course. This study aims to introduce an effective self-learning tool to engineers and graduate students who are working on power electronics. The proposed web-based remote laboratory consists of a power electronic test rig, a handmade measurement board, a control platform, and a LabVIEW-based user interface program. Although the developed system is a web-based remote accessible laboratory for advanced power electronics courses, the system can also be used to control and monitor a multi-mode single-leg power converter in stand-alone mode. Compared with other similar web-based remote laboratories, the developed laboratory is suitable for undergraduate and

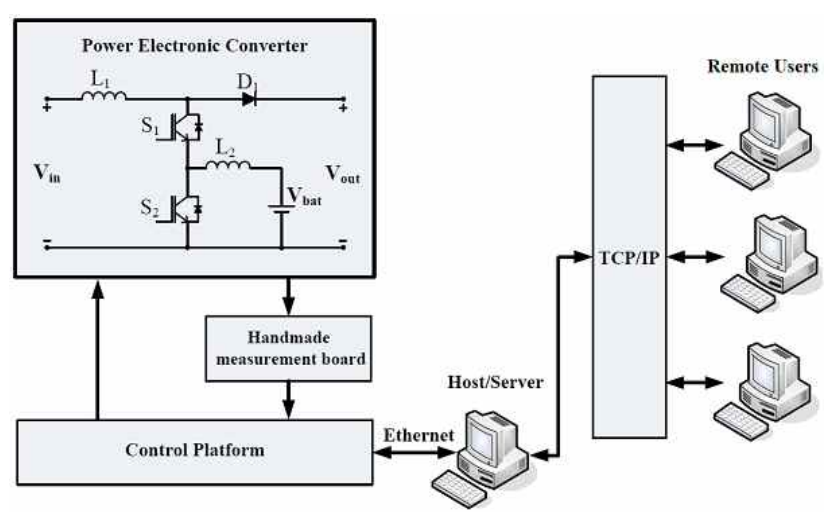

Fig. 1. Block diagram of the proposed remote laboratory architecture.

postgraduate students, as well as for researchers who are working on power electronics.

The rest of this paper is organized as follows. Section II introduces the hardware structure of the laboratory and the operation of the multi-mode single-leg power converter. Section III explains the software architecture of the system. Section IV presents the experiment results of a case study for the multi-mode single-leg power converter. Section V provides several educational outcomes. Finally, Section VI concludes the paper.

\section{LABORATORY ARCHITECTURE DESIGN}

\section{A. Laboratory Setup Overview}

Laboratory operation is based on server/client architecture, in which all pieces of hardware are on the server side and the system is administrated by the server. However, a personal computer with Internet connection is adequate for clients. The block diagram of the proposed remote laboratory architecture is shown in Fig. 1. This remote laboratory setup has four hardware components, namely: (1) host/server, (2) control platform, (3) handmade measurement board, and (4) power electronic converter at the server side. These hardware components are described in the following section.

1) Host/Server: The host/server is the administrative unit of the system. This unit transfers commands obtained from the client to the control platform via Ethernet connection, collects data obtained from the system, and sends the results back to the client. A user interface prepared with LabVIEW software is used to send commands and display results from clients. Remote users can select the control structure, change the reference voltage and system control parameters, and monitor the voltage and current waveforms through the user interface.

2) Control Platform: A PowerDNA $®$ (Distributed Networked Automation) -PPC8 data acquisition (DAQ) cube, which is a compact, rugged, Ethernet-based DAQ interface, is employed as the control platform. This interface is ideally suited for a wide variety of industrial, aerospace, and laboratory DAQ 
and control applications [20]. Depending on the application requirement, one or more PowerDNA ${ }^{\circledR}$ cube can be configured to obtain a specific I/O. In this study, for example, an AI-205 analog input board that offers four A/D channels with input ranges up to $\pm 100 \mathrm{~V}, 18$ bit resolution, $250 \mathrm{kS} / \mathrm{s}$ simultaneous sampling, and full channel-to-channel isolation is used to acquire analog signals for the power electronic converter. An AI-205 board features a three-stage polyphase finite input response filter that provides digital filtering capability in real time [21]. A CT-601 counter/timer/pulse-width modulation (PWM) board was used to generate two independent PWM signals for the insulated-gate bipolar transistors (IGBTs) in the converter. The CT-601 board is electrically identical with the AI-205 board and provides eight independent 32 bit channels. Each channel exhibits overvoltage protection and optoisolation. They perform up/down counting in a number of flexible modes by using values from a load register and two compare registers. They can also function as an event counter, perform width/period measurements, and run in quadrature-encode mode, wherein the user sets the counting direction. For the output modes, the layer offers one shot and universal PWM operation [22].

3) Handmade Measurement Board: A handmade measurement board is used to signal the level scaling part of the web-based remote laboratory. Through this board, the voltage and current signals obtained from the converter are reduced to the appropriate level for the AI-205 analog input board. The handmade measurement board consists of Hall-effect sensors, two voltage sensors (LEM-LV-25P), and two current sensors (LEM-LA-100P), which are used to measure the output of the power electronic converter, battery voltages $\left(V_{\text {out }}, V_{\text {bat }}\right)$, and L1 and L2 inductance currents $\left(I_{L 1}\right.$, $\left.I_{L 2}\right)$. These sensors convert the measured voltage and current signal levels into voltage signal levels that are acceptable to the I/O board. The sensors also function as an isolation barrier between the power electronic converter and the $\mathrm{I} / \mathrm{O}$ board. Hence, a safe operation is achieved for the remote laboratory system.

4) Power Electronic Converter: The topology chosen for the power electronic converter is a multi-mode single-leg converter. This converter includes two switches $\left(S_{1}, S_{2}\right)$, two inductors $\left(L_{1}, L_{2}\right)$, and a diode $\left(D_{1}\right)$. It can simultaneously operate in boost and buck converter modes. For example, the converter can simultaneously boost the generated voltage and charge/discharge storage devices, such as batteries and ultra-capacitors. A detailed analysis of this converter, its characteristics, and the selection of different components is presented in [19].

\section{B. Controller Structures of the Converter}

The operation of the proposed multi-mode single-leg converter can be analyzed at four different modes, namely, boost, boost-buck, boost-boost, and battery boost modes, as shown in Fig. 2. The following section explains the operation of these modes.

1) Main Boost Mode: The control structure of the main boost mode is illustrated in Fig. 2(a). Boost converter operation is performed to boost the main voltage source by chopping it with $S_{1}$ and $S_{2}$ switches. Both switches change position with the same duty cycle in this mode. The output voltage of the main boost mode operation can be written by using the traditional boost converter equation as follows:

$$
v_{\text {out }}=\frac{1}{1-D} V_{\text {in }},
$$

where

$$
D=\frac{T_{o n}}{T_{S}}
$$

2) Boost-Buck Mode: This mode assumes that the duty ratio of $S_{1}$ is longer than that of $S_{2}$. The input voltage is accordingly boosted when $S_{1}$ and $S_{2}$ are "ON." When $S_{1}$ remains "ON" while $S_{2}$ is turned "OFF," input voltages supply energy to the load and charge the battery. Fig. 2(b) illustrates the control structure of the boost-buck mode. To determine the output of the boost converter for this mode, the equation is transformed as follows:

$$
v_{\text {out }}=\frac{1}{1-D_{\text {boost }}} V_{\text {in }},
$$

where

$$
D_{\text {boost }}=\frac{T_{\text {on_boost }}}{T_{\text {s_boost }}} .
$$

To charge the battery, the equation is transformed into

$$
v_{\text {battery }}=D_{\text {buck }} V_{\text {in }} \text {, }
$$

where

$$
D_{\text {buck }}=\frac{T_{\text {on_buck }}}{T_{s_{-} \text {boost }}} .
$$

3) Boost-Boost Mode: This mode presents the opposite case from that of the boost-buck mode, in which the duty ratio of $S_{1}$ is longer than that of $S_{2}$. This mode allows the battery to discharge energy to the inverter when input energy generation is insufficient. Fig. 2(c) illustrates the control structure of the boost-boost mode. This mode boosts the input voltage while discharging the battery to supply the load. The equations for this mode are as follows:

$$
v_{\text {out }}=\frac{1}{1-D_{\text {boost } 1}} V_{\text {in }},
$$

where

$$
D_{b o o s t 1}=\frac{T_{o n \_b o o s t 1}}{T_{s}} ;
$$




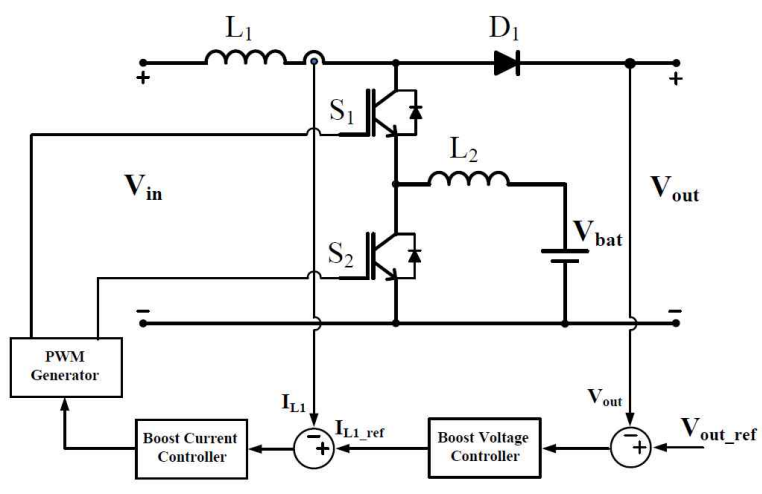

(a) Main Boost Mode.

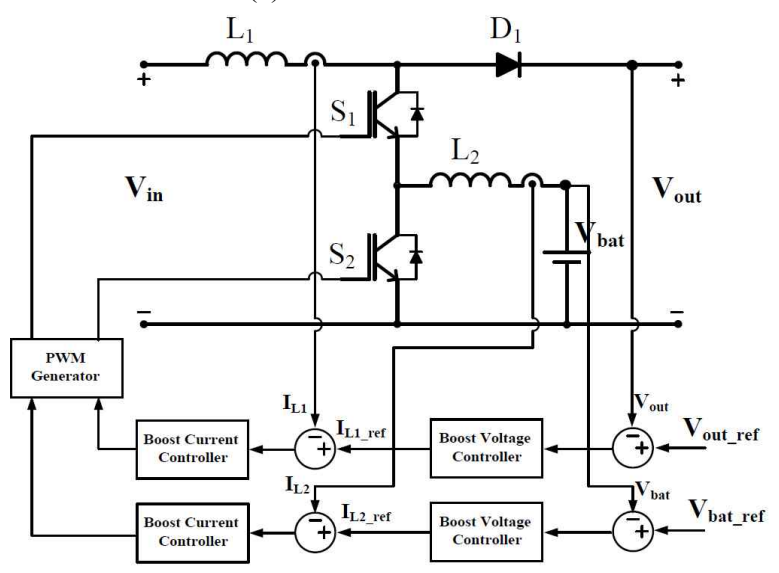

(c) Boost-Boost Mode.

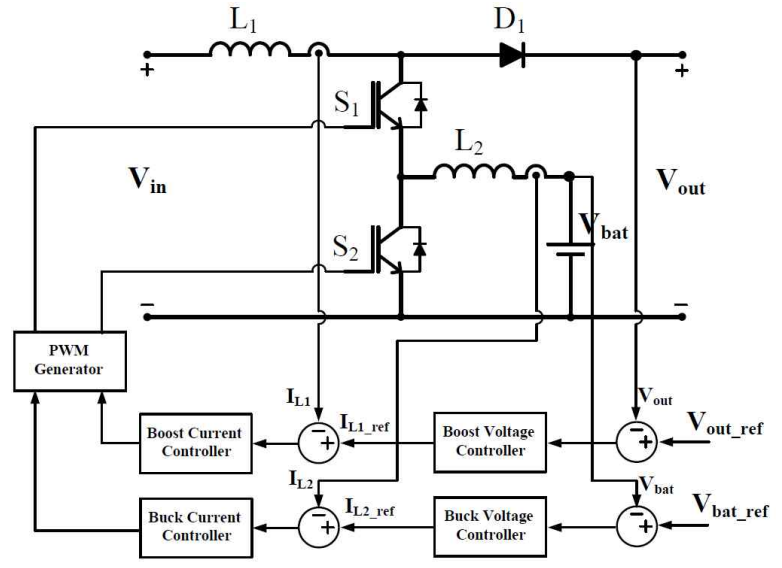

(b) Boost-Buck Mode.

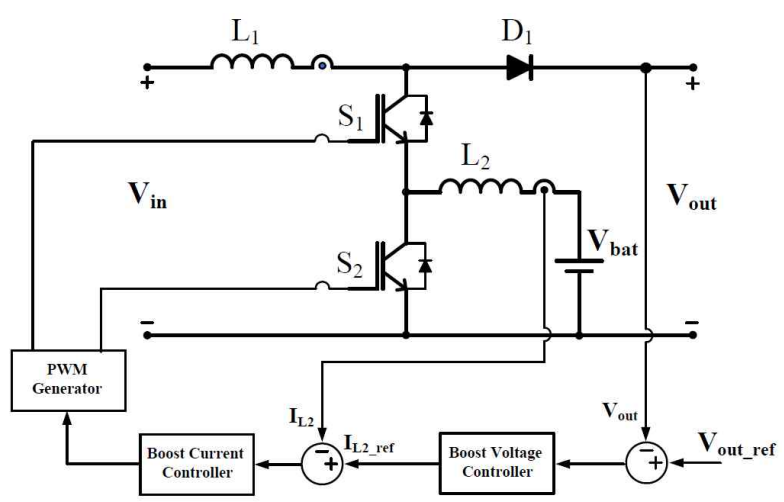

(d) Battery Boost Mode.

Fig. 2. Block diagram of the control algorithms for each operation mode.

and

$$
v_{\text {out }}=\frac{1}{1-D_{\text {boost } 2}} V_{\text {in }} \text {, }
$$

where

$$
D_{\text {boost } 2}=\frac{T_{\text {on_boost } 2_{2}}}{T_{s}} .
$$

4) Battery Boost Mode: The battery boost mode is useful in cases with input fault, such as cloud cover or damaged modules. Given the modification made on the converter, the state of $S_{1}$ does not have any effect on converter operation. Fig. 2(d) illustrates the control structure of the battery boost mode. The output voltage of this mode can be described by the following equation:

$$
v_{\text {out }}=\frac{1}{1-D} V_{\text {bat }} .
$$

The duty ratio of $S_{2}$ is as follows:

$$
D=\frac{T_{o n}}{T_{s}} .
$$

\section{SOFTWARE ARCHITECTURE}

The block diagram for the software architecture of the proposed remote laboratory system is shown in Fig. 3. System operation is administrated by the server application software created with LabVIEW programming language. The server application software is composed of six main modules, namely, a LabVIEW web publishing tool, a user login interface, a user interface, an analog input subsystem, a proportional-integral-derivative (PID) control subsystem, and a PWM generation subsystem.

\section{A. LabVIEW Web Publishing Tool}

Applications frequently require networking interfaces for machine-to-machine communication, remote monitoring, or remote control of an embedded device. The proliferation of the Internet and networking infrastructure simplifies the task of connecting distributed hardware over existing physical networks. LabVIEW provides a variety of options to establish communication among software applications. In the proposed remote laboratory, LabVIEW web publishing tool is used to provide a web-based interface for communication with existing LabVIEW applications.

Through LabVIEW web publishing tool, front panels can 


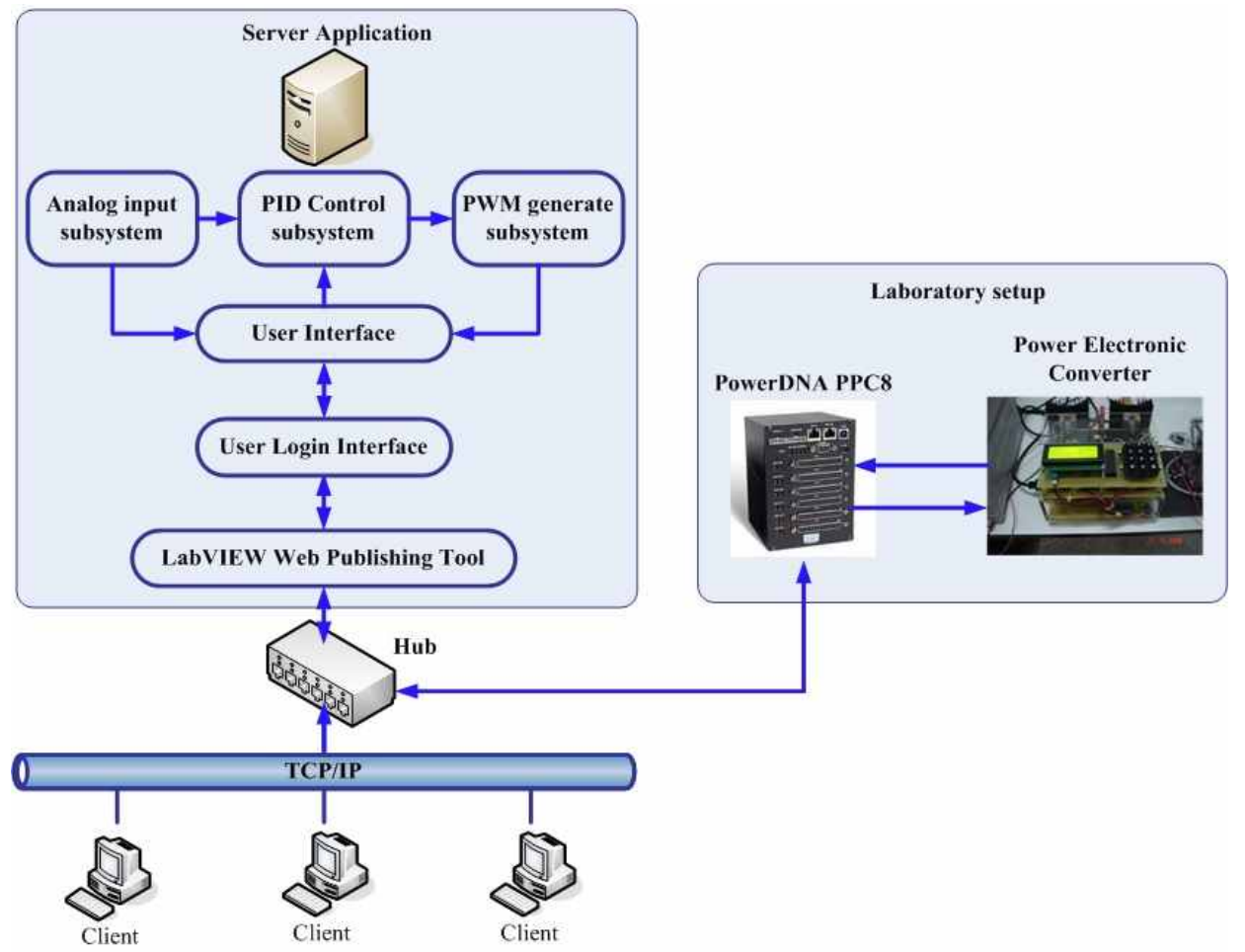

Fig. 3. Software architecture of the proposed remote laboratory.

be quickly and effortlessly published on the web. Once published, anyone on the web with the proper permission can access and control the experiment without installing LabVIEW software. LabVIEW web publishing tool automatically creates and stores an HTML document for a selected LabVIEW virtual instrument. When a remote viewer enters an appropriate URL address, the LabVIEW front panel appears in the web browser.

\section{B. Remote Login Interface}

Remote users can connect to the power electronic laboratory from any personal computer in the Gazi University local network. Given that the developed laboratory is protected by a password, remote users must have a valid user name and password to manage and authenticate the system. When remote users enter their user name and password, these data are encrypted by the data encryption standard and sent to the server with the IP address of the remote user. The server application searches for the received user name and password in a local database and a session with a $40 \mathrm{~min}$ time-out period is started if the user name and password are confirmed. Given the firewall applications of the university, the system cannot be accessed from outside the local network at present. The front panel and block diagram screens of the remote log-in interface are shown in Fig. 4.

\section{User Interface}

In this study, a LabVIEW-based user interface software is developed to control experimental setups and measure required values. The front panel of the user interface software is shown in Fig. 5. The front panel consists of three main parts, namely: (1) the selection part of the operation mode for the multi-mode single-leg converter, (2) the modified part of the PID control parameters and the reference voltage values, and (3) the monitoring part of the measured signal. Remote users can choose operating modes in the selection part of the operation mode for the multi-mode single-leg converter. This part has four selection options for operation modes, as mentioned in Section II. Remote users can perform four experiments with a single user interface. The PID control parameters and reference voltage values can be modified by using the selection part of the PID control parameters and the reference voltage values. In this part, the PID controller and the reference voltage inputs are changed according to converter operation modes. For example, if remote users select mode 1 , they can see the boost current controller and boost voltage controller; if remote users select mode 2, they can see the boost-buck current controller and boost-buck voltage controller. Thus, remote users can see the effects of different control parameters on the system. The experiment results are shown in the last part of the front panel. In this part, remote users can simultaneously see the measured signals, such as the converter output voltage, battery voltage, and inductor currents from the multi-mode single-leg converter. Users can also see the PWM signals applied to the switching device. In addition, the frequency response of each controller can be easily monitored. Hence, clicking on the 

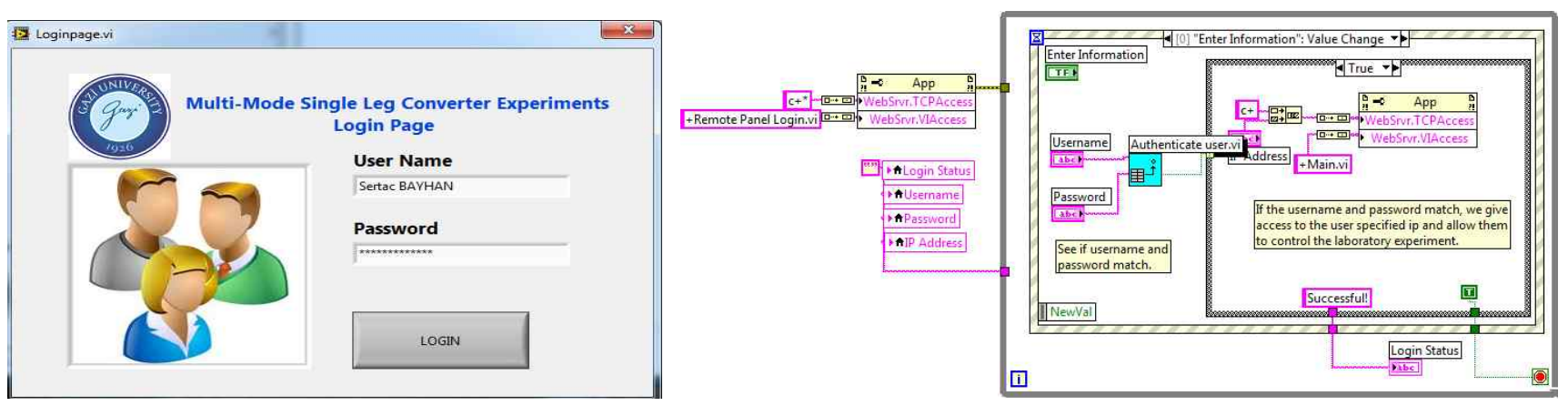

Fig. 4. Front panel and block diagram of the remote log-in interface.

Converter modes selection part

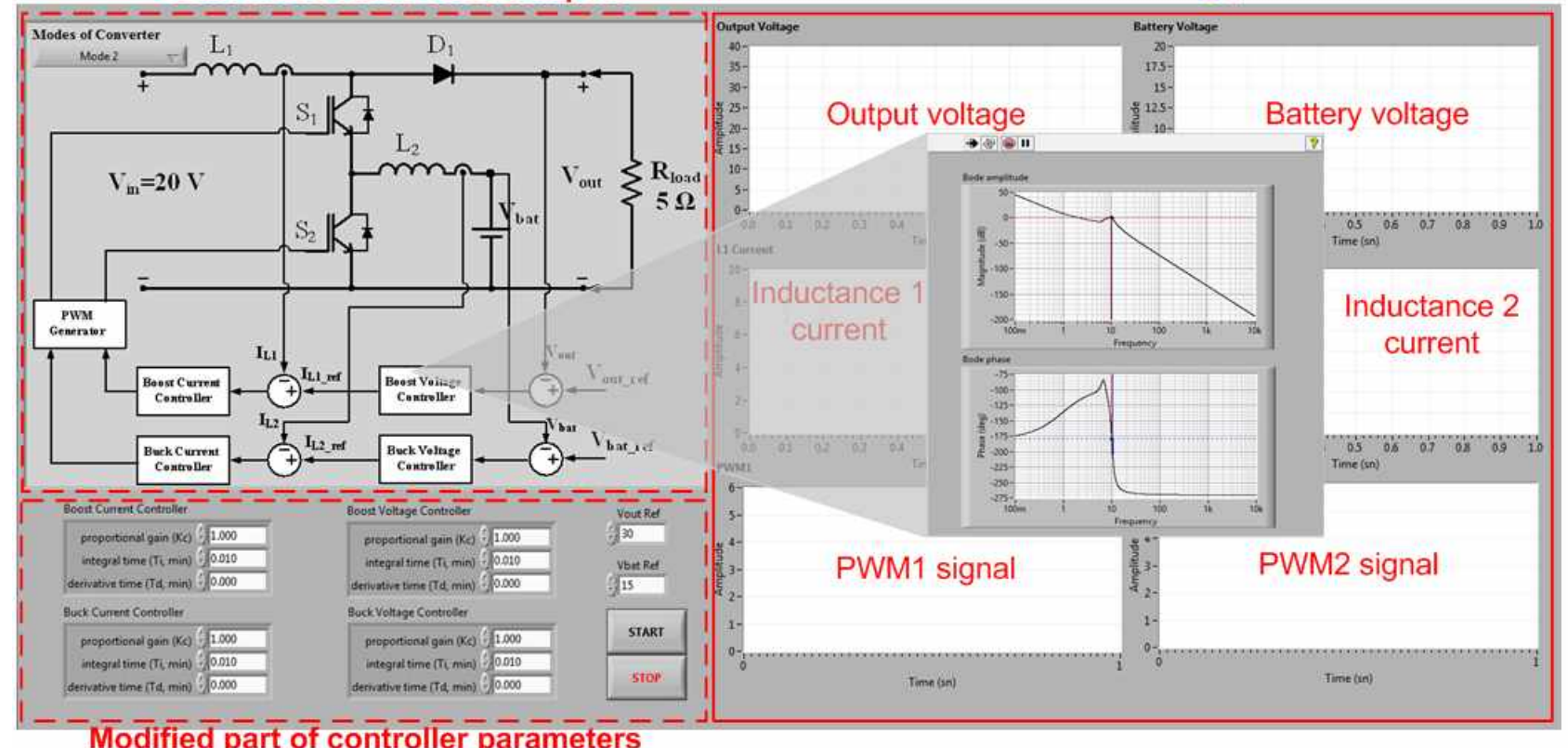

Fig. 5. Front panel of the user interface software.

controller blocks, which are located in the system block diagram, is insufficient. Users can effectively learn the effect of the controller parameters on the output of the multi-mode single-leg converter.

\section{Analog Input Subsystem}

The function of the analog input subsystem is to sample and quantize the analog signal that comes from the multi-mode single-leg converter by using the AI-205 analog input board. Once the analog input subsystem has started, it connects to the AI-205 analog input board via TCP/IP protocol and reads the output voltage, battery voltage, $L_{I}$ inductance current, and $L_{2}$ inductance current by using the "pdna://10.12.64.200/dev0/Ai0:3" IP address of the analog board. All analog signals are read simultaneously with a 12.8 $\mathrm{kHz}$ sampling rate and transferred to the PID control subsystem and the user interface.

\section{E. PID Control Subsystem}

The function of the PID control subsystem is to control the

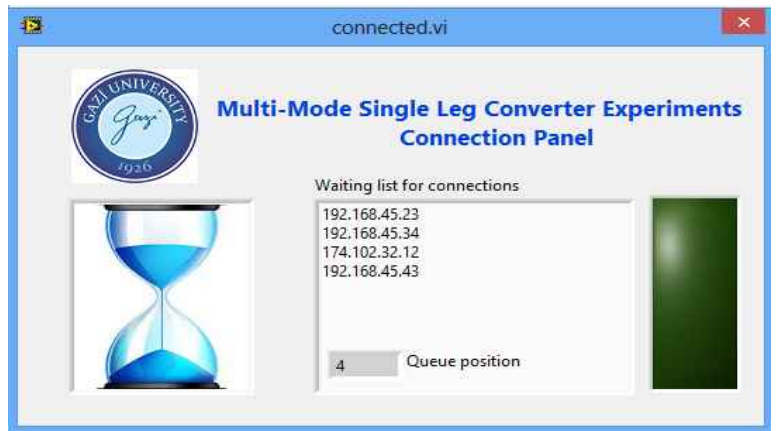

Fig. 6. Screenshot of the remote connection panel.

output and battery voltage of the multi-mode single-leg converter. For this process, the error signal obtained from a comparison between the reference and measured values is applied to the PID controller. The regulated signal is then sent to the PWM subsystem to generate PWM signals for the power electronic converter. The numbers of PID controllers used in the system vary depending on the operation mode of 


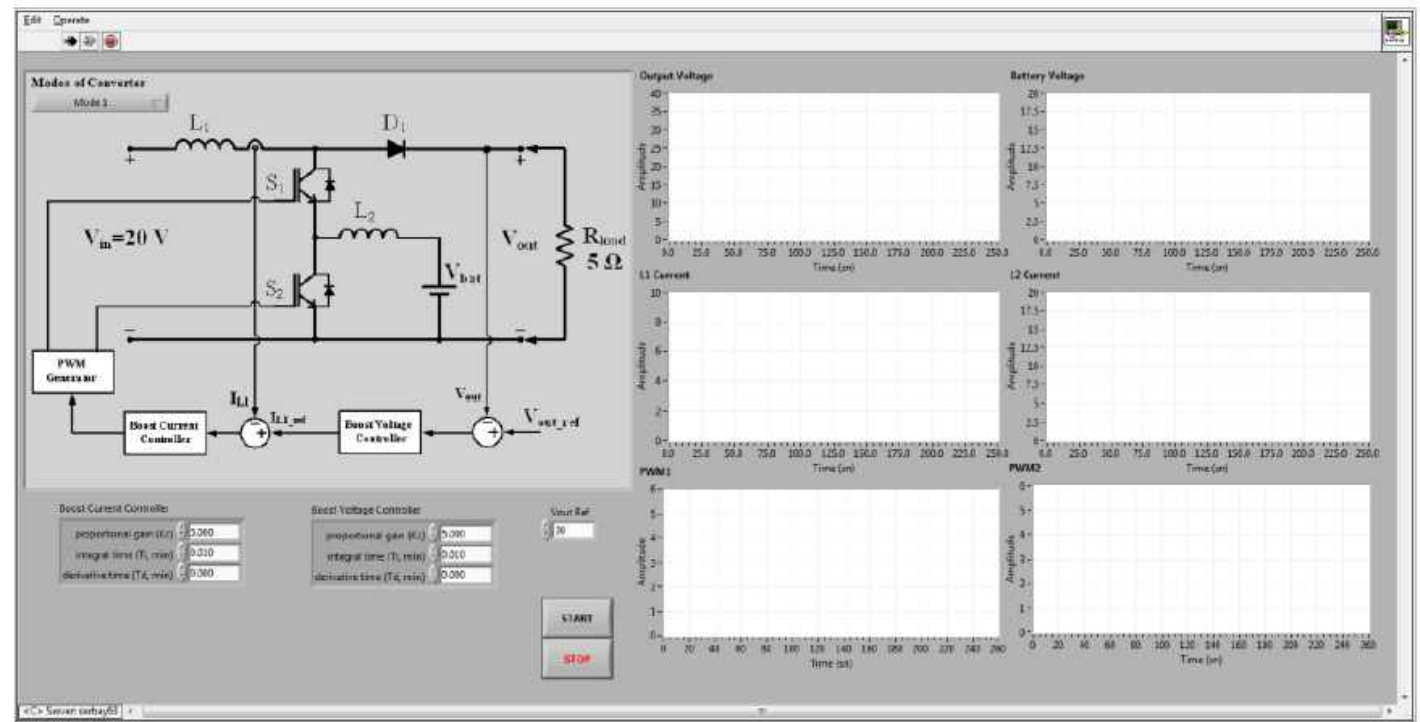

Fig. 7. Default screen of the remote laboratory interface.

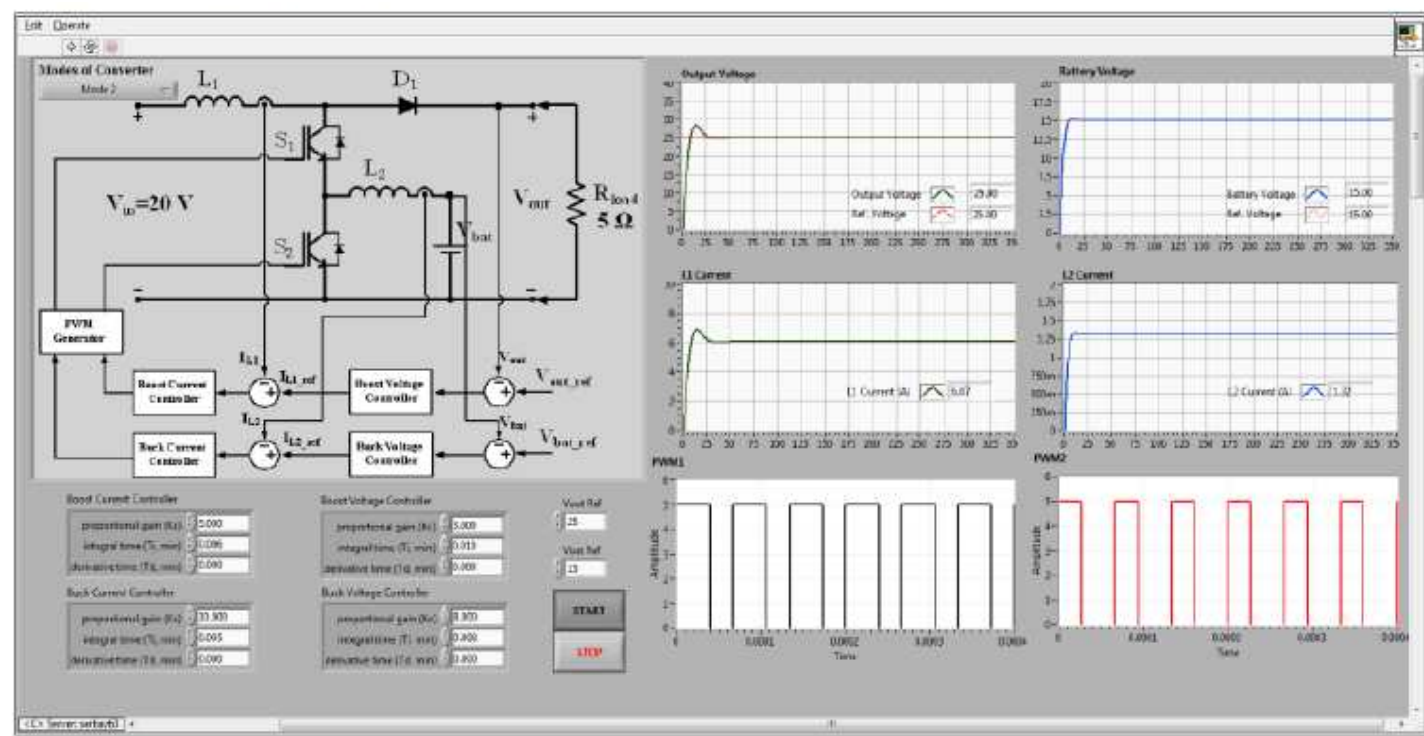

Fig. 8. Screenshot of the experiment running under the boost-buck mode.

the converter.

\section{F. PWM Generation Subsystem}

The task of the PWM generation subsystem is to generate two independent PWM signals by using the CT-601 counter/timer/PWM board. The connection between the subsystem and the CT-601 counter/timer/PWM board is ensured by the TCP/IP protocol. The duty cycle of the PWM signals is automatically adjusted according to the data obtained from the PID control subsystem. The generated PWM signals are sent to the user interface software to allow users to see them. Thus, users can view the PWM signal duty cycle online according to the operation mode of the multi-mode single-leg converter.

\section{PRACTICAL CASES}

This section shows several experiments that are developed by using the remote laboratory described in this paper. First, a typical remote experiment session is described, which summarizes how a remote user interacts with the laboratory. Second, an experiment on the multi-mode single-leg converter control with mode 2 (boost-buck mode) is explained.

\section{A. Typical Remote Experimental Session}

A remote user must be identified through his/her user name and password for remote connection as described in Section III.

Users can connect to the remote laboratory system through 

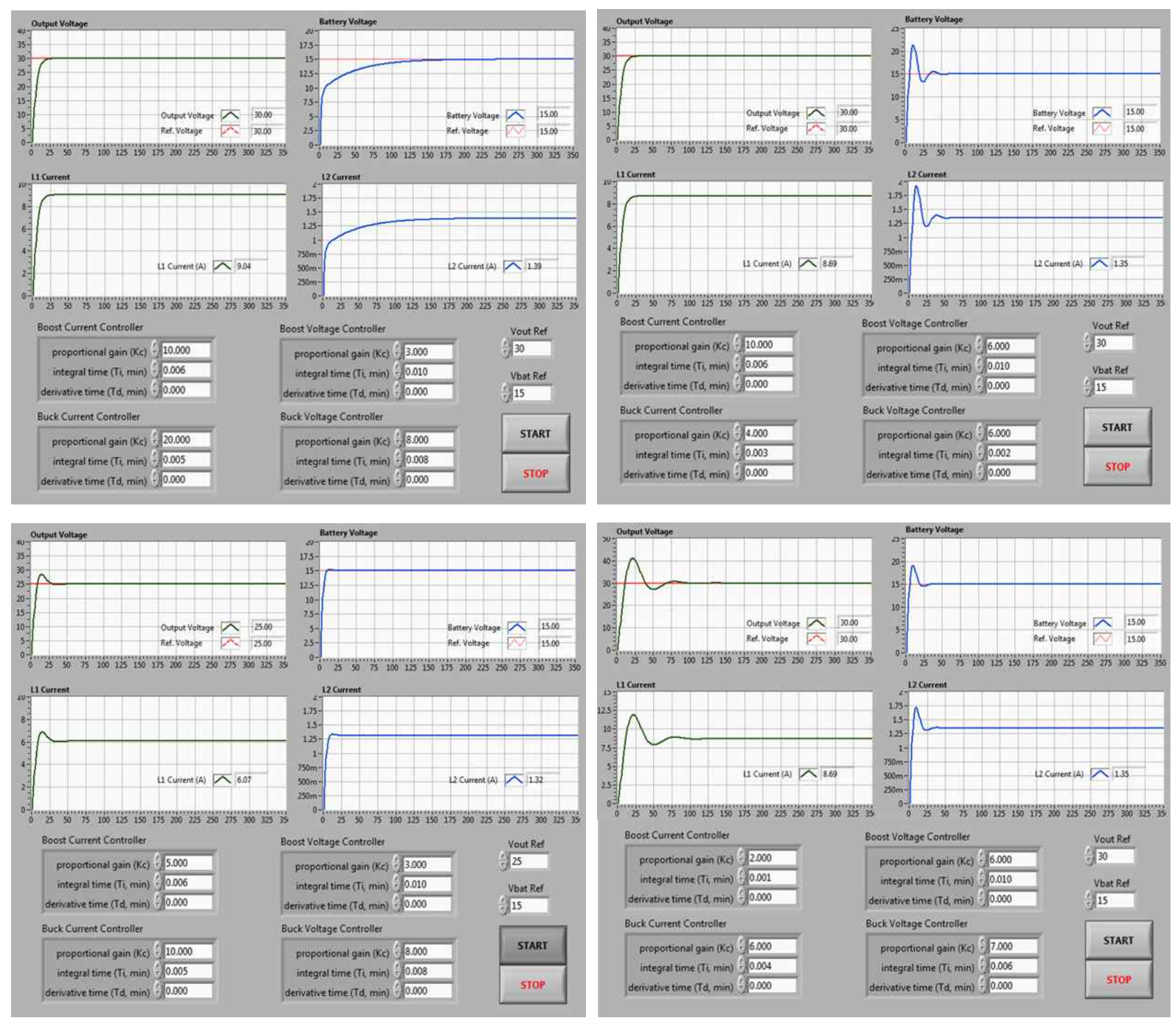

Fig. 9. Screenshots of the boost-buck mode operation under different controller parameters.

an Internet browser, such as Internet Explorer and Google Chrome. No other package program is required.

Once the remote log-in interface program is running in the Internet browser, the remote user has to click the "LOG-IN" button to access the laboratory (Fig. 4). If another remote user is present in the system, an information window will appear on the screen as shown in Fig. 6. This screen shows the waiting IP address and its queue position. When the remote log-in interface grants access to the laboratory, the controlling indicator is active and an experimental session starts.

Fig. 7 shows that the remote user can choose the modes of the converter, introduce the control parameters, and set the reference values. The experiment is then ready to start. With the experiment running, the user interface represents the acquired data in real time as shown in Fig. 8.

\section{B. Case Study: Operation of the Buck-Boost Mode}

In this experiment, mode 2 (boost-buck mode) is selected for the multi-mode single-leg converter. The multi-mode single-leg converter simultaneously operates as a boost converter and a buck converter at this mode. The converter boosts $V_{\text {in }}$ to $V_{\text {out }}$ and charges the battery, as described in Section II. During the experimental studies, the input voltage of the converter is set to $20 \mathrm{~V}$, and $5 \mathrm{ohm}$ resistive load is connected to the converter output. The experimental test rig parameters are provided in Table I.

Fig. 8 shows the user interface screen during boost-buck mode. Data entry dialog boxes in this mode are the PID controller parameters, namely, proportional coefficient $(K c)$, integral time $(T i)$, and derivative time $(T d)$, as well as the output voltage and battery voltage. Remote users can perform experiments by clicking the START button after entering 


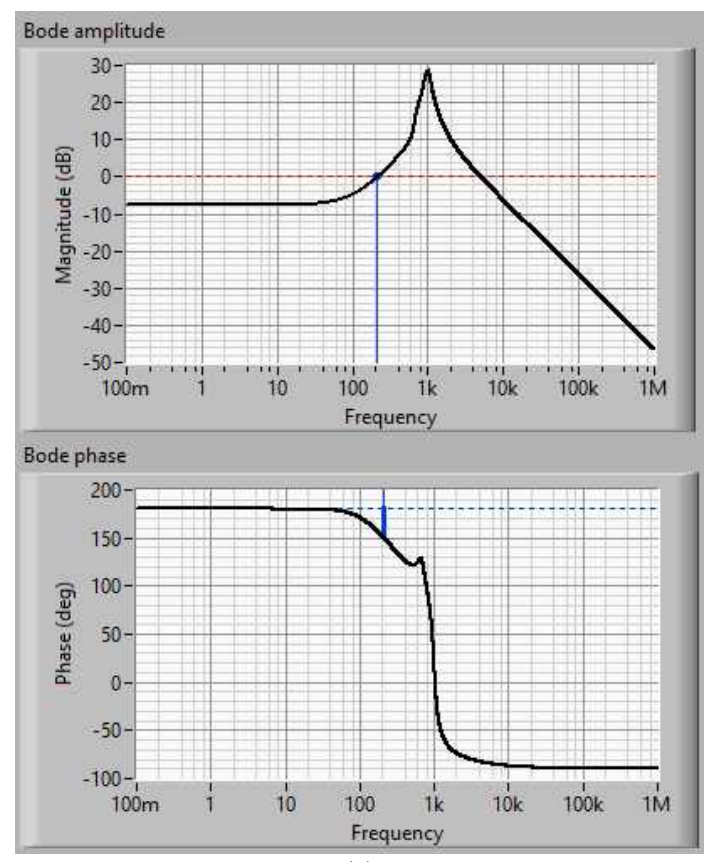

(a)
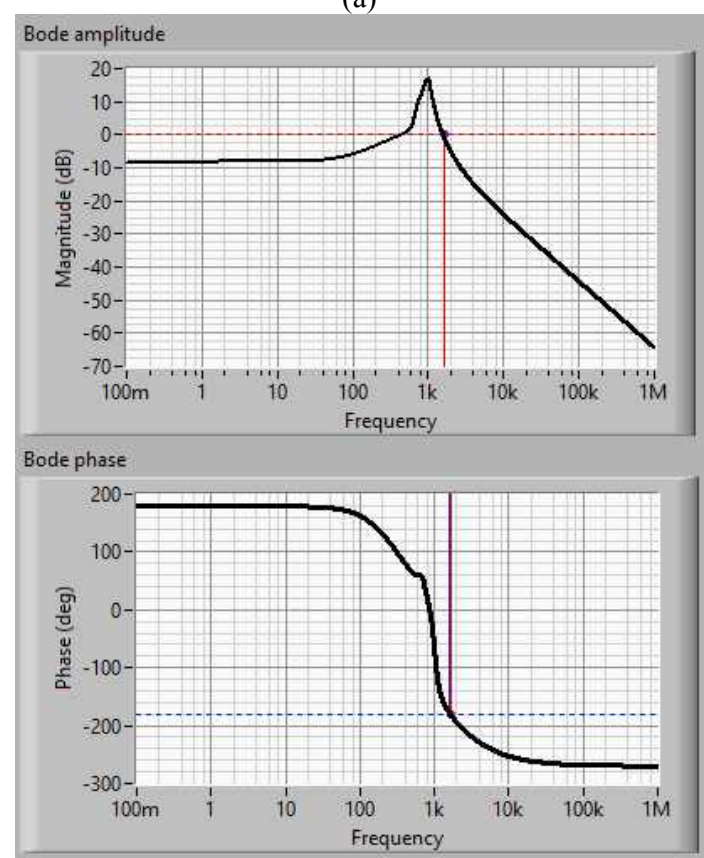

(b)

Fig. 10. Frequency response. (a) Voltage controller. (b) Current controller for the boost converter.

these parameters. Fig. 9 shows the screenshots of four different experiment results. Users can select different control parameters for a constant output and battery voltage level. During these studies, the output and battery voltages are set to $30 \mathrm{~V}$ and $15 \mathrm{~V}$, respectively.

According to the different controller parameters selected by users, the output and battery voltages, as well as the output and battery currents, can be easily monitored online. Users can also follow the PWM signals of the IGBTs on the same
TABLE I

EXPERIMENTAL PARAMETERS

\begin{tabular}{llll}
\hline Input voltage & $20 \mathrm{~V}$ & $\begin{array}{l}\text { Switching } \\
\text { frequency }\end{array}$ & $15 \mathrm{kHz}$ \\
Battery & $14.4 \mathrm{~V}, 8.1 \mathrm{Ah}$ & IGBT & $100 \mathrm{~A}, 1200 \mathrm{~V}$ \\
Inductor (L1) & $1 \mathrm{mH}$ & Inductor (L2) & $0.5 \mathrm{mH}$ \\
Output voltage & $30 \mathrm{~V}$ & Load & $5 \Omega$ \\
\hline
\end{tabular}

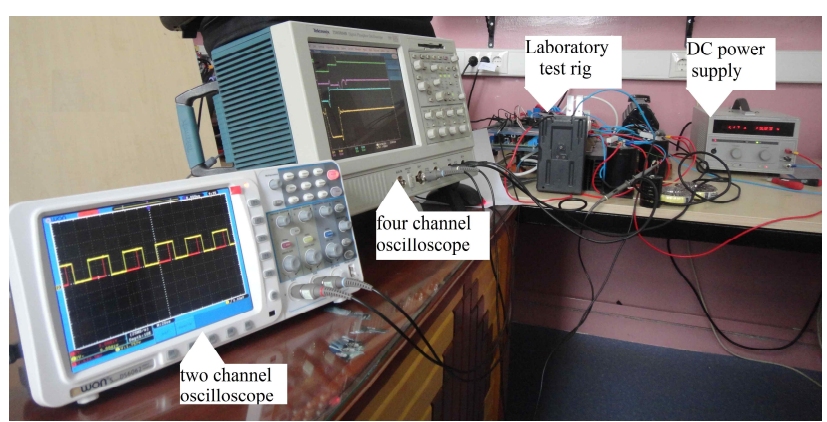

Fig. 11. Photograph of the traditional laboratory experimental setup for the multi-mode single-leg converter.

screen. Furthermore, the frequency responses of the voltage and current controllers while the converter is running on mode 2 are given in Figs. 10(a) and 10(b), respectively. With the help of the watch behavior function of the system during the experimental studies, users can determine the effects of the controller parameters on the system and decide whether the system is stable.

\section{EdUCATIONAL OUTCOMES}

The designed remote laboratory is being used to conduct practices in a masteral subject on knowledge regarding advanced converters. Analyzing the results of a survey conducted by students provides an opportunity to comment on the performance of the remote laboratory. According to the feedbacks of the students, the main advantages of the laboratory are visuality, usability, a user-friendly interface, real-world experiments and measurements, possibility of data storage, and online use of a complex laboratory. Nevertheless, students with slow Internet connection have experienced problems in experimental data reception. Other students have found the experiments difficult to understand without the assistance of an instructor. Consequently, the feedbacks received from students who performed remote laboratory studies have shown that the proposed laboratory is a useful tool for remote or traditional education. However, it is not an alternative to real laboratory practice but has complementary roles for students and instructors.

\section{CONCLUSIONS}

In traditional laboratory applications, the establishment of an experimental assembly, running the experiment, and obtaining results are time-consuming processes. Traditional laboratories also have several important disadvantages, such as students or users facing high-voltage risk or failure of 
measuring instruments and equipment because of improper connection of devices. Measuring all signals with a single device is also difficult because of grounding problem and insufficient measurement ports. For example, Fig. 11 shows the traditional laboratory test rig and measuring devices to implement a web-based laboratory. Two digital oscilloscopes are necessary to measure the test rig parameters (output voltage, battery voltage, and so on). Such test rig is difficult to establish for all students because of the high cost of this equipment. Another drawback of this laboratory is that signals are difficult to compare because all signals are not on the same screen.

In this study, a novel web-based remote laboratory application is designed and implemented as a part of an advanced power electronics course. The aforementioned disadvantages of a traditional laboratory are eliminated. A multi-mode single-leg converter is chosen as an example of the laboratory application because four operation modes are possible with such converter. This study aims to introduce an effective self-learning tool for engineers and graduate students working on power electronics. The main advantage of the proposed system is helping students perform practical experiments remotely.

\section{REFERENCES}

[1] M. Stefanovic, V. Cvjetkovic, M. Matijevic, and V. Simic, "A LabVIEW-based remote laboratory experiments for control engineering education," Comp. App. Eng. Educ, Vol. 19, No. 3 pp.538-549, Sep. 2011.

[2] R. Puerto, L. M. Jimenez, and O. Reinoso, "Remote control laboratory via internet using matlab and simulink," Comp. App. Eng. Educ., Vol. 18, No.4, pp. 694-702, Dec. 2010.

[3] A. Rojko, D. Hercog, and K. Jazenik, "Power engineering and motion control web laboratory: Design, implementation, and evaluation of mechatronics course," IEEE Trans. Ind. Electron., Vol. 57, No.10, pp. 3343-3354, Oct. 2010.

[4] M. T. Restivo, J. Mendes, A. M. Lopes, C. M. Silva, and F. Chouzal, "A remote laboratory in engineering measurement," IEEE Trans. Ind. Electron., Vol. 56, No. 12, pp. 4836-4843, Dec. 2009.

[5] J. A. Asumadu, R. Tanner, J. Fitzmaurice, M. Kelly, H. Ogunleye, J. Belter, and S.C. Koh, "A web based electrical and electronics remote wiring and measurement laboratory (RwmLAB) instrument," IEEE Trans. Instrum. Meas., Vol. 54, No. 1, pp. 38-44, Feb. 2005.

[6] S. Azaklar and H. Korkmaz, "A remotely accessible and configurable electronics laboratory implementation by using LabVIEW," Comp. App. Eng. Educ., Vol. 18, No. 4, pp. 709-720, Dec. 2010.

[7] A. Yayla and A. Akar, "Web based real time remote laboratory with LabVIEW access for analog and digital communication courses," Istanbul Univ. Jour. Electrical \& Electronics Eng., Vol. 8, No. 2, pp. 671-681, 2008.

[8] C. S. Tzafestas, N. Palaiologou, and M. Alifragis, "Virtual and remote robotic laboratory: comparative experimental evaluation," IEEE Trans. Educ., Vol. 49, No. 3, pp. 360-369, Aug. 2006.

[9] C. A. Jara, F. A. Candelas, and F. Torres, "Virtual and remote laboratory for robotics e-learning," 18th European Symposium on Computer Aided Process Engineering, 2008.
[10] S. L. T. Marin, F. J. B. Garcia, R. M. Torres, S. G. Vazquez, and A. J. L. Moreno, "Implementation of a web-based educational tool for digital signal processing teaching using the technological acceptance model," IEEE Trans. Educ., Vol. 48, No.4, pp. 632-641, Nov. 2005.

[11] E. Irmak, R. Bayındır, I. Colak, and M. Soysal, "A remote laboratory experiment for 4-quadrant control of a DC motor," Comp. App. Eng. Educ., Vol. 19, No. 4, pp. 747-758, Dec. 2011.

[12] A. P. J. Chandra and C. R. Venugopal, "Novel design solutions for remote access, acquire and control of laboratory experiments on DC machines," IEEE Trans. Instrum. and Meas., Vol. 61, No. 2, pp. 349-357, Feb. 2012.

[13] G. Bal and S. Bayhan, "Internet based virtual electric machine lab: Switched reluctance motor," Application of Information and Communication Technologies-AICT2010, 2010.

[14] I. Colak, S. Demirbas, S. Sagıroglu, and E. Irmak, "A novel web-based laboratory for DC motor experiments," Сomp. App. Eng. Educ., Vol. 19, No. 1, pp. 125-135, Mar. 2011.

[15] A. Yazidi, H. Henao, G. Capolino, and F. Filippeti, “A web-based remote laboratory for monitoring and diagnosis of AC electrical machines," IEEE Trans. Ind. Electron., Vol. 58, No. 10, pp. 4950-4959, Oct. 2011.

[16] F. J. Rodriquez, C. Giron, J. Emilio, A. Hernandez, S. Cobreces, and P. Martin, "Remote laboratory for experimentation with multilevel power converters," IEEE Trans. Ind. Electron., Vol. 56, No.7, pp. 2450-2463, Jul. 2009.

[17] S. C. Wang and Y. H. Liu, "Software-reconfigurable e-learning platform for power electronics courses," IEEE Trans. Ind. Electron., Vol. 55, No. 6, pp. 2416-2424, Jun. 2008.

[18] S. Demirbas and G. Mutlu, "Internet based toolkit for simulation of DC/DC converters, international conference on power engineering," in Energy and Electrical Drives, 2011.

[19] T. Park and T. Kim, "Novel energy conversion system based on a multimode single-leg power converter," IEEE Trans. Power Electron., Vol. 28, No. 1, pp. 213-220, Jan. 2013.

[20] PowerDNA PPC8 data acquisition cube product manual, United Electronic Industries, http: http://www.ueidaq.com/data-acquisition-chassis/ethernet-da q/dna-ppc8.html

[21] PowerDNA AI-205 analog input board product manual, United Electronic Industries, http: http://www.ueidaq.com/data-acquisition-layers/analog-input /simultaneous-sampling/dna/dna-ai-205.html

[22] PowerDNA CT-601 counter/timers/PWM board product manual, United Electronic Industries, http: $\mathrm{http}: / / \mathrm{www}$.ueidaq.com/data-acquisition-layers/counter-time rs-pwm-quadrature/dna/dna-ct-601.html

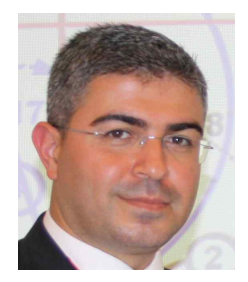

Sertac Bayhan was born in Siverek, Turkey in 1981. He received his B.Sc., M.Sc., and Ph.D. degrees from the Faculty of Technical Education, Gazi University, Ankara, Turkey in 2006, 2008, and 2012, respectively. He is currently a Postdoctoral Research Associate in Texas A\&M University at Qatar, Doha, Qatar. His main interests are power electronics, wind energy generation and grid integration, application of power electronics, power quality, and electric machines and drives. 